\title{
LA PLATERÍA CIVIL COMPOSTELANA EN EL TRÁNSITO DEL SIGLO XIX AL XX A TRAVÉS DE LAS FOTOGRAFÍAS INÉDITAS DEL ARCHIVO DEL PLATERO RICARDO MARTÍNEZ COSTOYA*
}

Ana Pérez Varela

Universidade de Santiago de Compostela

Data recepción: 2018/05/31

Data aceptación: 2018/12/17

Contacto autora: ana.perez.varela@usc.es

ORCID: https://orcid.org/0000-0001-7195-1565

\section{RESUMEN}

Ricardo Martínez Costoya fue uno de los artífices más importantes de la Compostela del cambio del siglo XIX al XX, protagonizada por el efervescente contexto de reactivación de las peregrinaciones y la actividad artística tras la segunda inventio de los restos del Apóstol en 1879. El archivo personal que guardó el platero, compuesto por fotografías y bocetos, y hasta ahora inédito, reúne una valiosa muestra de piezas de platería, y resulta especialmente interesante para estudiar obras civiles, muy escasas en Galicia. El catálogo del artífice, con más de ciento cincuenta piezas y sesenta bocetos, constituye el conjunto más numeroso de obras conocidas de un platero gallego y demuestra un rico y variado eclecticismo que combina gran cantidad de estilos e influencias artísticas.

Palabras clave: platería, Santiago de Compostela, bocetos de platería, siglo XIX, piezas civiles

\section{ABSTRACT}

Ricardo Martínez Costoya was one of Santiago de Compostela's leading artists at the turn of the twentieth century, within the context of the revival of the pilgrimage and the frenetic artistic activity that followed the second inventio of the remains of the Apostle in 1879. The silversmith's personal archive, consisting of photographs and sketches and unpublished to date, provides a valuable demonstration of silversmithing and is of special interest when it comes to studying civil pieces, which are very rare in Galicia. Comprising more than 150 objects and 60 sketches, the artist's catalogue constitutes the largest collection of known pieces by a Galician silversmith and reveals a rich and varied eclecticism that encompasses a wide range of styles and artistic influences.

Keywords: silversmithing, Santiago de Compostela, silversmith sketches, 19th century, civil pieces

\section{Algunas notas sobre el platero Ricardo Martínez Costoya (1859-1927)}

Ricardo Martínez Costoya nació el 20 de diciembre de 1859 en Santiago de Compostela'. En esta ciudad se formó como platero bajo la enseñanza del mejor orfebre de la época, José Losada², a quien debemos las dos obras de platería más emblemáticas de la catedral compostelana: el célebre botafumeiro (1851), y el inicio del proyecto de la urna apostólica (1884-1891)². La relación de enseñanza-aprendizaje entre ambos queda reconocida y destacada por el propio Martínez, quien se autodenomina como "sucesor de Losada" en 
los membretes comerciales, grabados por Enrique Mayer, que adornan sus facturas emitidas a la Catedral ${ }^{4}$.

Como oficial del obrador de Losada, Martínez trabaja en la urna argentífera que custodia los huesos de Santiago, que se realizó en el estimulante contexto de la segunda inventio, cuando los restos fueron recuperados tras permanecer tres siglos perdidos en el subsuelo catedralicio ${ }^{5}$. Además, nuestro platero realizó en solitario la bella repisa broncínea sobre la cual reposa la pieza, culminando así el conjunto funerario en $1891^{6}$. Esta opera prima trajo consigo principalmente dos consecuencias: la primera, el inicio de su vida laboral con una fama e importancia ya reconocidas por un hito histórico; y la segunda, la enorme influencia que ejerció dicha obra en su posterior catálogo. Como podemos comprobar en un vistazo al conjunto de sus obras conservadas, la urna fue una sombra que estilísticamente estuvo presente en muchas de las piezas que realizó.

Tras participar en la urna, Martínez quedó al frente del obrador de Losada, situado en los bajos del claustro catedralicio, hacia la calle Fonseca, lugar que en las cuentas de la fábrica se registra con el nombre de "tienda debajo de la veeduría"7. Nuestro platero pagó un alquiler de trescientos sesenta y cinco reales anuales a la Catedral a partir de 1886, cuando su maestro se retiró y fue ingresado en el manicomio de Conxo. Ricardo Martínez no sólo heredó el espacio físico de su maestro, sino también su cargo de platero oficial de la Catedral ${ }^{9}$. Las nutridas facturas entregadas a la fábrica hasta 1924 revelan una relación larga y prolífica, en la que realizó todo tipo de piezas, a la vez que mantenía, arreglaba y limpiaba la plata existente ${ }^{10}$.

La fama de Martínez se manifiesta al analizar los catálogos de las exposiciones regionales y de artes y oficios, que fueron una constante en el contexto del cambio de siglo, centrado en la necesidad de mostrar los continuos avances en una sociedad dominada por el progreso y el avance como nunca antes"1. Obtuvo la medalla de oro en la Exposición de Industrias Artísticas de Barcelona de $1892^{12}$, triunfando en ámbito nacional en una temprana fecha en su carrera. Fruto de ese éxito debió ser el encargo de una custodia para el convento de las adoratrices de la ciudad condal ${ }^{13}$. En 1896, ganó dos medallas en el Congreso Eucarístico ${ }^{14}$ y la Exposición Regional ${ }^{15}$ celebrados en Lugo el mismo año. En 1909, no sólo participó en la gran Exposición Regional Gallega celebrada en Santiago en año santo, sino que formó parte de su organización como miembro de la Comisión Arqueológica'16.

La gran cantidad de noticias referidas a Ricardo Martínez en la prensa de la época también da cuenta de la importancia que tuvo el artífice en la Compostela del cambio de siglo. Hemos hallado referencias hemerográficas en más de treinta periódicos contemporáneos al platero procedentes de toda Galicia, entre las que destacan las más de cien ocasiones en las que lo nombra El Eco de Santiago. La mayoría reseñan piezas o su participación en exposiciones, y nos han permitido identificar un buen número de obras inéditas. Otras tienen que ver con su familia o su implicación en diversos organismos públicos, como los jurados populares, la Cámara de Comercio y el Círculo Mercantil de Santiago. La misma prensa se hace eco de su muerte, en 1927, a la edad de sesenta y siete años ${ }^{17}$.

\section{El archivo personal del platero}

A raíz de nuestros trabajos de investigación sobre Ricardo Martínez, contactaron con nosotros los descendientes del platero, quienes tuvieron el interés y la amabilidad de poner a nuestra disposición las pertenencias del artista ${ }^{18}$. Sus bisnietos han conservado una especie de pequeño archivo que Martínez recopiló a lo largo de su vida. Las fuentes que el platero atesoró son de diversa naturaleza y nos han permitido derivar nuestra investigación de forma fructífera hacia cuestiones que desconocíamos.

Además de fotografías familiares, correspondencia ${ }^{19}$, o incluso pequeñas piezas de plata ${ }^{20}$, el archivo está compuesto por tres grupos de fuentes muy valiosas para reconstruir su trayectoria artística, y nos ha dado a conocer una cantidad muy importante de piezas. Aunque en su mayor parte las obras fotografiadas no se conservan o se hallan en paradero desconocido, hemos podido examinarlas gracias a este material. Por tanto, han venido a enriquecer lo que sabemos sobre su obra, y han posibilitado el establecimiento de 
conclusiones más certeras sobre su producción en cuestiones de tipología, estilo, clientela y difusión.

Hemos dividido este tipo de información entre tres categorías: fotografías de piezas propias, fotografías/láminas de modelos y bocetos. En este estudio nos centraremos únicamente en la primera categoría, principalmente por dos razones. La primera es que las fotografías de piezas propias constituyen el grupo no sólo más numeroso de los tres, sino también con una mayor riqueza de tipos y variedad de modelos. La segunda, es que este grupo contiene un gran número de piezas identificables y otras de las que tenemos noticia documental, lo que nos permite establecer conclusiones más certeras sobre su producción y clientela.

Sin embargo, no queremos dejar de realizar alguna puntualización sobre el resto de las fuentes. En cuanto a las fotografías/láminas de modelos, constituyen una serie de obras ajenas al platero, pero que debieron servir para su estudio personal y como fuente de inspiración. Por ejemplo, conservaba una fotografía anotada de la custodia augsburguesa que donó la reina Mariana de Neoburgo a la colegiata de Santa María do Campo en A Coruña ${ }^{21}$. Sabemos que la pieza se exhibió en la Exposición Regional de 1909, en la cual, como ya hemos señalado, Martínez formó parte de la organización. Como platero, seguramente tuviese que ver directamente con la selección de esta obra concreta. También guardaba una lámina que presenta distintos tipos de marcos y formas de presentar retratos y cuadros, sin duda de utilidad para él a la hora de realizar estas piezas. Así mismo, hemos hallado una hoja de patrones decorativos de rejería guipuzcoana que reproducen las barandas de la escalera principal de la casa consistorial de San Sebastián, y que nos remiten inmediatamente a modelos ornamentales utilizados por Martínez, por lo que debieron servirle de patrón ${ }^{22}$.

Finalmente, encontramos también fotografías de obras identificables, que debieron de ser una fuente de inspiración, como un candelero de Benvenuto Cellini para Francisco I, dos custodias parroquiales de Teruel23, o el cáliz que realizó su maestro José Losada para la catedral compostela$n^{24}$. Entre sus papeles encontramos también una fotografía del grabado del Pórtico de la Gloria de Enrique Mayer sobre dibujo de Ángel Bar, fechado en 1892, del que se conservan varios ejemplares en la Catedral25. A juzgar por la fotografía, es posible que Martínez realizase el marco que ciñe ese ejemplar concreto y por eso guardase una imagen de éste.

Con respecto a los bocetos, éstos constituyen un interesantísimo y nutrido grupo de cincuenta y nueve dibujos. Creemos que se trata de un material inédito de gran importancia, ya que se conservan muy pocos bocetos de plateros dentro del ámbito de la platería española. Éstos están a menudo relacionados con los exámenes de maestría ${ }^{26}$, siendo difícil hallar dibujos realizados por iniciativa propia para ensayar las piezas. En relación con esto, este conjunto presenta gran interés dentro de la comprensión del proceso creativo del oficio de platero, del que a efectos prácticos sabemos muy poco. Pensamos que la importancia de esta colección merece un estudio individualizado, del que esperamos ocuparnos en otra ocasión.

\section{Consideraciones generales sobre las fo- tografías}

La mayor parte de las fotografías del archivo del platero son de estudio, y aparecen firmadas por los fotógrafos compostelanos de la época: Manuel Chicharro Bisí, Juan Almeida, Bernardo Escribano, Ernesto Carrero o J. Varela27. Las protagonistas de éstas son siempre las piezas, que se presentan en primer plano sobre fondo oscuro.

A veces discernir si una fotografía es una pieza ajena o propia, teniendo en cuenta el eclecticismo de su catálogo, resulta tarea complicada. Algunas de las obras no dejan lugar a dudas, ya que, como veremos, son piezas que se conservan y que hemos podido estudiar personalmente. Además de éstas, creemos haber identificado hasta setenta piezas propias del platero en paradero desconocido, número que aumenta considerablemente su catálogo y lo eleva a más de ciento cincuenta ejemplares. Pensamos que, hasta la fecha, se trata del conjunto de obra más extenso de un platero gallego del que tenemos conocimiento, y certifica lo prolífica y variada que fue su producción. 


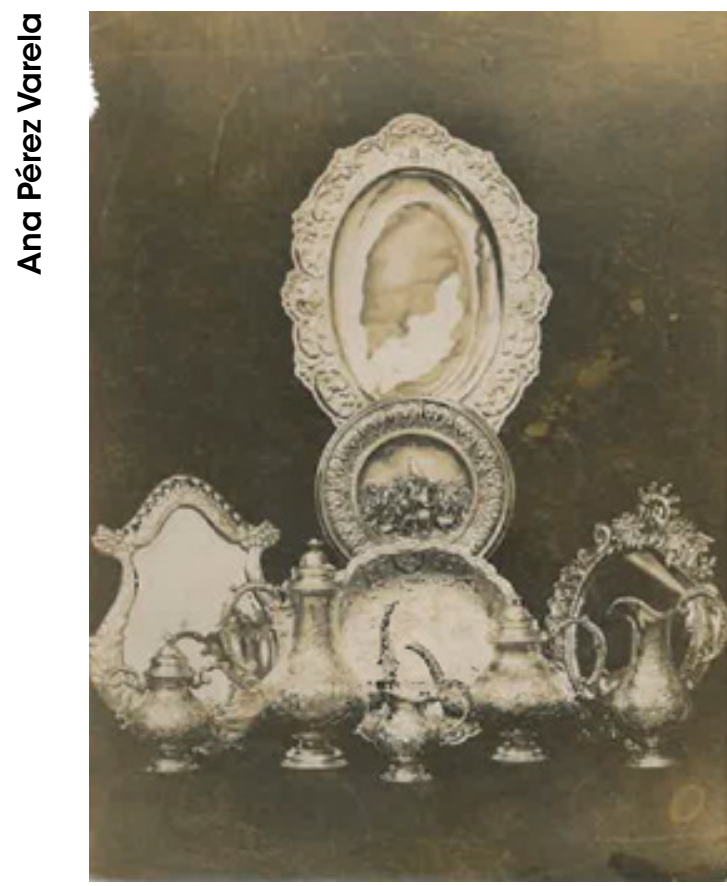

Fig. 1. Conjunto de vajilla, fotografía cedida por los hermanos de Diego Agudo, bisnietos de RMC

Además, estas fotografías resultan particularmente interesantes para conocer piezas de platería civil. Ésta, con respecto a la platería sacra, es un tipo que tiende a conservarse mucho menos en número en cualquier época y territorio. Debido a su naturaleza de uso, los cambios de moda, o la riqueza inherente al material -que convirtió a menudo las piezas en valor de cambio-, la gran mayoría de obras de platería civil que se han fabricado a lo largo de la historia se ha perdido, o permanecen guardadas por sus dueños. Bouza Brey organizó en 1962 una exposición que reunió obras de platería civil compostelana hasta finales del siglo XIX. Su catálogo incorpora muy pocas imágenes, y la mayoría corresponden a Ricardo Martínez ${ }^{28}$. Esto puede darnos una idea de la importancia que tuvo el platero como representante histórico de este tipo de encargos.

Otras fotografías del archivo son recortes de láminas publicadas. Pertenecen todas a la obra periódica editada por Mira Leroy, Materiales y Documentos de Arte Españo/29 que tuvo una versión francesa ${ }^{30}$. La revista, que funcionaba mediante suscripciones, estuvo activa de 1900 a 1906, y sin

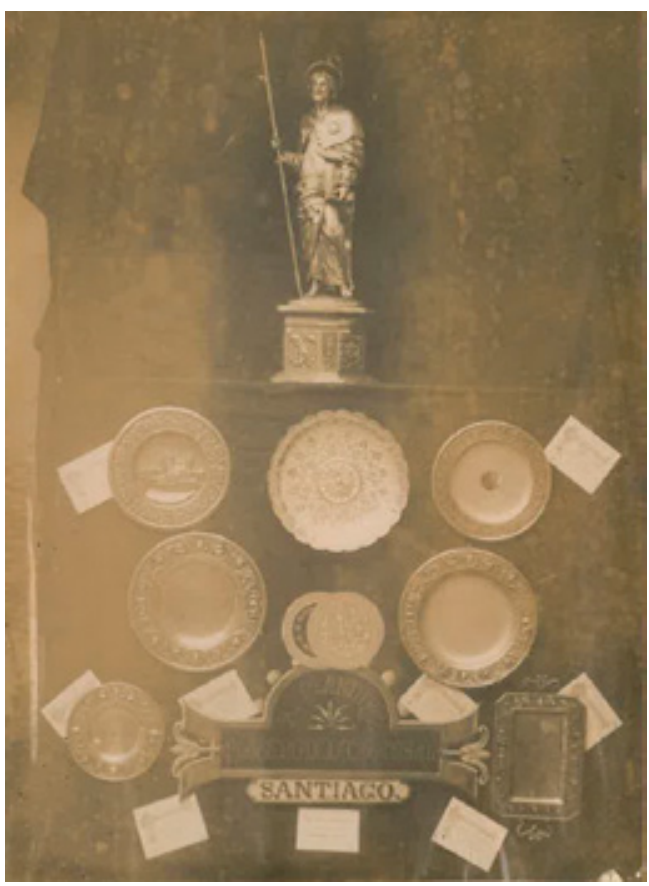

Fig. 2. Expositor de Ricardo Martínez Costoya en la Exposición Regional de Lugo, 1896, fotografía cedida por los hermanos de Diego Agudo, bisnietos de RMC

ningún tipo de comentario artístico, publicaba exclusivamente láminas de obras de arte nacionales. Toda la revista tiene una clara preferencia, en la línea decimonónica del cambio de siglo, entre lo neogótico y el art decó modernista, dos estilos, por otro lado, muy presentes en el catálogo de Martínez. Su aparición en esta publicación nos habla no sólo de su difusión nacional e incluso internacional, sino también de la puesta en valor en la propia época de una platería ecléctica que respondía a los gustos artísticos del cambio de centuria.

En la versión española tenemos constancia de la aparición de una lámina con cuatro bandejas de Ricardo Martínez al que se le indica como "platero en Santiago de Galicia" ${ }^{31}$. Sólo conocemos otro platero gallego publicado, Eduardo Rey, que fue compañero suyo en la ejecución de la urna apostólica y probablemente también oficial del taller de José Losada32.

Más importante aún resulta su aparición en la versión francesa de la publicación, en la que contamos con hasta siete piezas. Gracias a esta revis- 


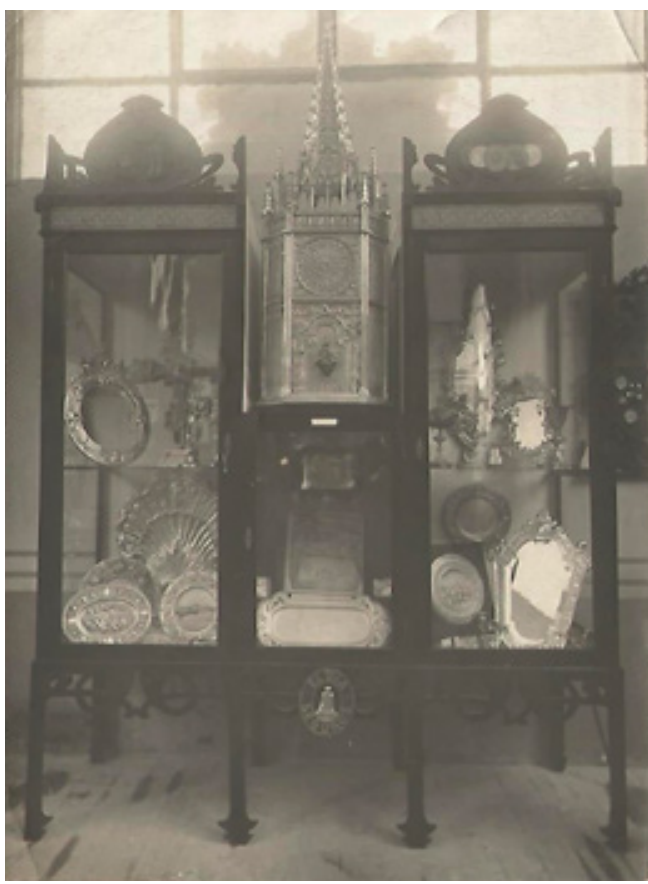

Fig. 3. Expositor de Ricardo Martínez Costoya en la Exposición Regional Gallega, 1909, fotografía cedida por los hermanos de Diego Agudo, bisnietos de RMC

ta conocemos el magnífico sagrario que realizó para el convento de la Enseñanza de Santiago; la custodia gótica para el convento de las adoratrices de Barcelona; una concha para el cardenal Martín de Herrera; y otras obras importantes para conocer platería civil, tales como un candelero, un candelabro o dos platos redondos decorados.

Creemos que Ricardo Martínez empleaba las imágenes de las publicaciones de Mira Leroy para su archivo personal, las cuales, junto con las fotografías propias tomadas a otras de sus piezas, constituían una especie de catálogo de muestras en el que la clientela podía encargar obras idénticas o similares, además de las propias piezas que pudiese tener en su tienda expuestas al público. Esta hipótesis se basa en que las láminas y fotografías aparecen recortadas y anotadas de forma manuscrita con datos relativos al precio y algunos apuntes sobre posibles variantes, tales como "esta [bandeja] puede ser lisa sin adornar", "espejo [de] luna bridada para colgar o sobre mesa", etc.

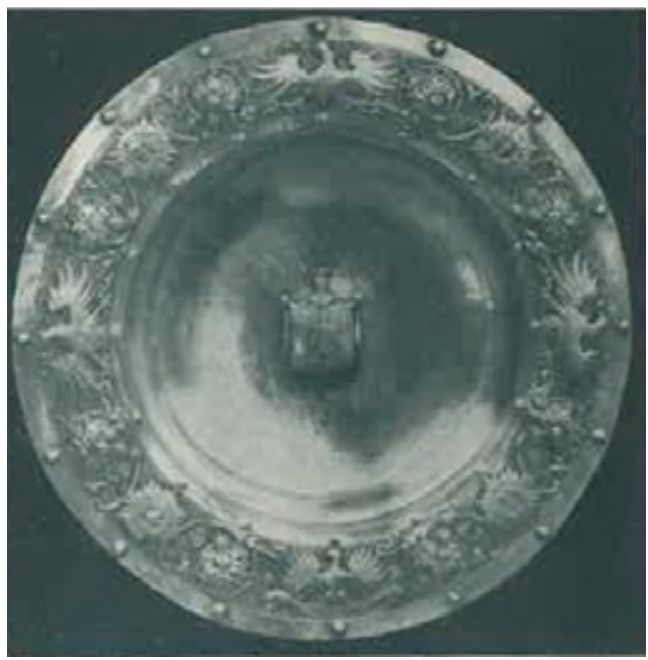

Fig. 4. Ricardo Martínez Costoya, Bandeja, fotografía cedida por los hermanos de Diego Agudo, bisnietos de RMC

En su archivo se guardan también tres interesantes fotografías de conjuntos. El primero (fig. 1), sin identificar, es un grupo compuesto por diferentes bandejas, cafeteras, azucareros y otras piezas de vajilla, así como espejos y uno de sus platos con relieve de la batalla de Clavijo. Otra fotografía (fig. 2) muestra su instalación en la Exposición Regional de Lugo (1896) donde observamos su célebre figura de Santiago peregrino ${ }^{33}$ junto a siete bandejas. La tercera (fig. 3) exhibe la vitrina presentada por el platero a la Exposición Regional de Santiago (1909). Acoge todo tipo de piezas, con el soberbio sagrario de la Enseñanza como pieza protagonista, rodeado de bandejas, espejos, y otras piezas reconocibles de su catálogo. Ambos documentos gráficos nos permiten conocer su participación en dichas muestras, y conocer la forma de exponer este tipo de obras, ya que los catálogos de la época raramente incluyen imágenes. Estas tres fotografías reúnen más de treinta y cinco piezas del platero.

\section{Las piezas de platería civil}

\section{Bandejas}

El archivo de Martínez nos ha permitido conocer veintiséis bandejas -además de las observadas en las fotografías de conjuntos-, de variados tamaños, formas y estilos históricos. En primer lugar, debemos descartar de nuestra lista una 


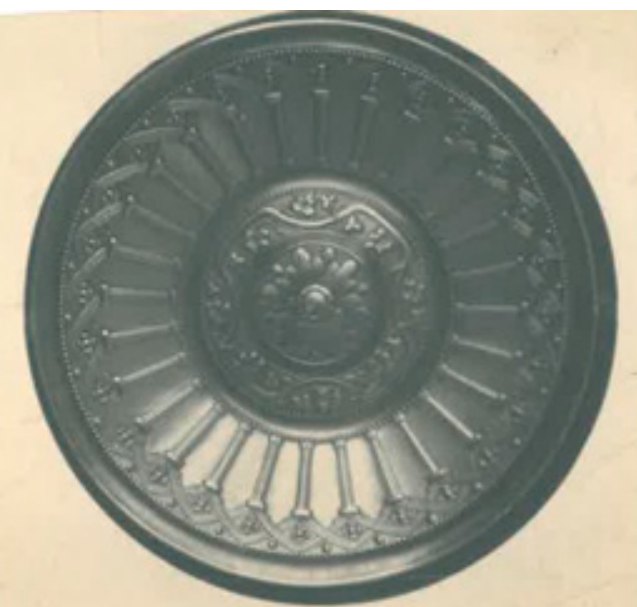

Fig. 5. Ricardo Martínez Costoya: Bandeja, fotografía cedida por los hermanos de Diego Agudo, bisnietos de RMC

bella concha para el cardenal Martín de Herrera, por presentar función sacra ${ }^{34}$. Entre las civiles, en primer lugar, tenemos un grupo de bandejas o platos de forma redonda. La mayoría de ellas ostentan amplias orillas profusamente decoradas y asiento liso.

Reconocemos algunas piezas conservadas hoy en día como la perteneciente a Joyería Ángel. Su orilla se decora de manera profusa con grandes hojas de acanto, flores y frutos, entre los que parecen encontrarse granadas y piñas. Los adornos son muy plásticos y demuestran su preocupación por diferenciar calidades táctiles y tridimensionalidad. La orilla está dividida en cuatro grandes secciones, y cada una de ellas se separa por un triglifo en relieve. Martínez guardaba en su archivo personal dos fotografías de esta misma bandeja, cada una de las cuales estaba anotada en su reverso con distintas indicaciones. La primera reza "30 onzas $x$ 30, 100 pesetas" y la segunda "30 x 30 cms, 125 pesetas / 150". Seguramente este tipo de bandeja fue uno de los muchos modelos de plato que la clientela podía encargar en su taller atendiendo al catálogo.

Otra bandeja reconocible es una pieza subastada en Madrid en 2013 $3^{35}$. Presenta amplia orilla adornada con motivos vegetales de tallos, hojas, tulipanes y pequeñas florecillas, y un borde exterior e interior troquelado en todo su perímetro, generando una serie de perlas separadas entre sí, un recurso muy empleado por el platero

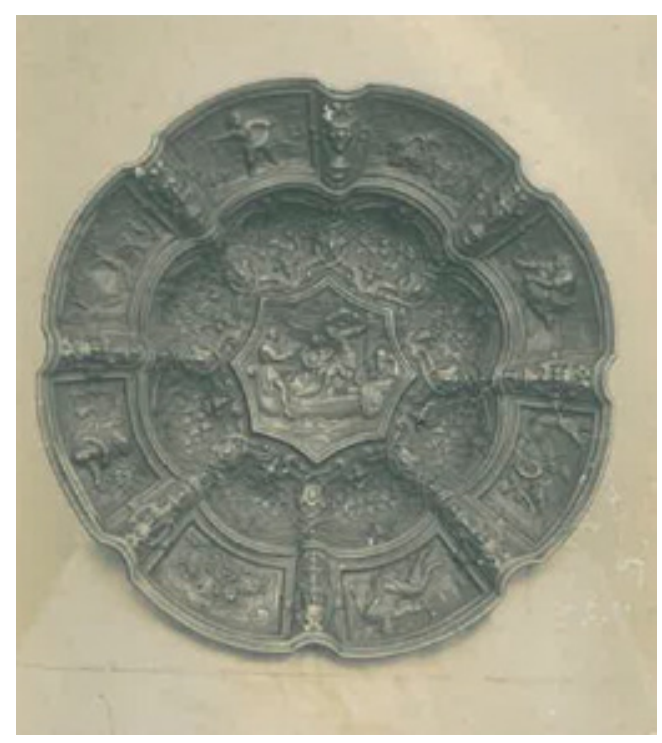

Fig. 6. Ricardo Martínez Costoya: Bandeja, fotografía cedida por los hermanos de Diego Agudo, bisnietos de RMC

en sus bandejas. Éste debió de ser otro modelo muy repetido, ya que en su archivo aparecen dos fotografías de piezas prácticamente idénticas, y una tercera que adapta el modelo a una bandeja ovalada. Aunque dos de ellas pueden parecernos especialmente similares, están anotadas en su reverso con diferentes medidas y sus patrones decorativos varían mínimamente. Uno de estos ejemplos fue publicado por Mira Leroy en su obra francesa ${ }^{36}$. Además, hemos conservado dos bocetos de la mano del platero que ensayan este adorno exacto.

Contamos con otros cuatro platos similares en paradero desconocido. Las grecas ornamentales varían patrones eclécticos de todos los estilos artísticos, desde cenefas vegetales a candelieri, patrones rococós de curva y contracurva entrelazando cartelas, cenefas zoomórficas, hasta un plato que presenta esquemas geométricos modernistas propios del art decó, muy originales. Hemos identificado una de ellas (fig. 4), publicada por Mira Leroy ${ }^{37}$ como la bandeja que le encargó en 1904 un diplomático de la embajada de España en Alemania, "cerca de la corte del Emperador Guillermo I", ya que como indica la prensa, ostenta un escudo central y una greca de "águilas imperiales entrelazadas con condecoraciones militares y otros motivos de ornamentación de 


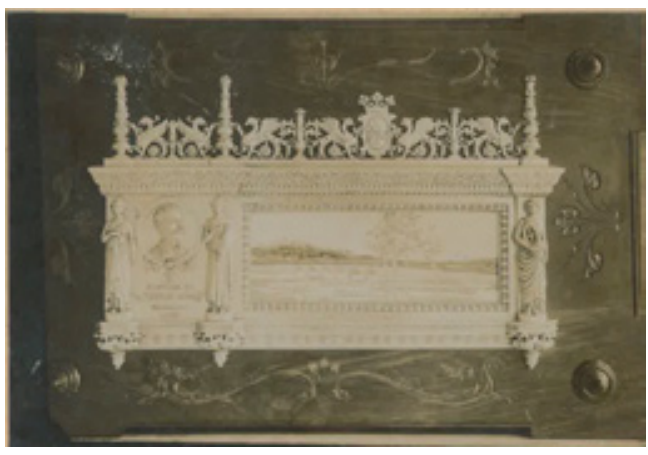

Fig. 7. Ricardo Martínez Costoya: Placa conmemorativa, fotografía cedida por los hermanos de Diego Agudo, bisnietos de RMC

gusto admirable" ${ }^{38}$. Otro de estos platos, podría corresponderse con una de las "bandejas [que] tienen en su contorno una greca y en el centro un escudo", reseñadas en prensa en $1897^{39}$, o con las bandejas alegóricas del comercio hechas por Ricardo Martínez de las que da cuenta un periódico en $1899^{40}$, ya que el escudo en este caso parece incorporar una rueda dentada, símbolo relacionado con la industria.

Así mismo, tenemos tres ejemplos de bandejas redondas con fina orilla que presentan ornamentación en la totalidad de su superficie. En primer lugar, un elegante plato publicado por Mira Leroy ${ }^{41}$, de desarrollado adorno vegetal ecléctico compuesto por entrelazados concéntricos de palmetas modernistas y haces de florecillas. En segundo lugar, contamos con dos bandejas casi idénticas (fig. 5) cuyo asiento está organizado en torno a un centro, compuesto por un adorno floral. Circunscribiéndolo, se despliega una gran columnata toscana sobre la que apoya una serie de originales arcadas ojivales entrelazadas. El hecho de que conservase dos fotografías que varían mínimamente el modelo nos indica que también debió de ser una pieza demandada en varias ocasiones.

También redonda, contamos con una bella pieza gallonada dividida en ocho secciones compartimentadas (fig. 6). La misma fotografía que guardaba el platero fue publicada por Bouza Brey en $1962^{42}$. Resulta uno de los ejemplos excepcionales de su catálogo por presentar la superficie totalmente cubierta por un programa iconográfico. Desgraciadamente, sus reproducciones fo-

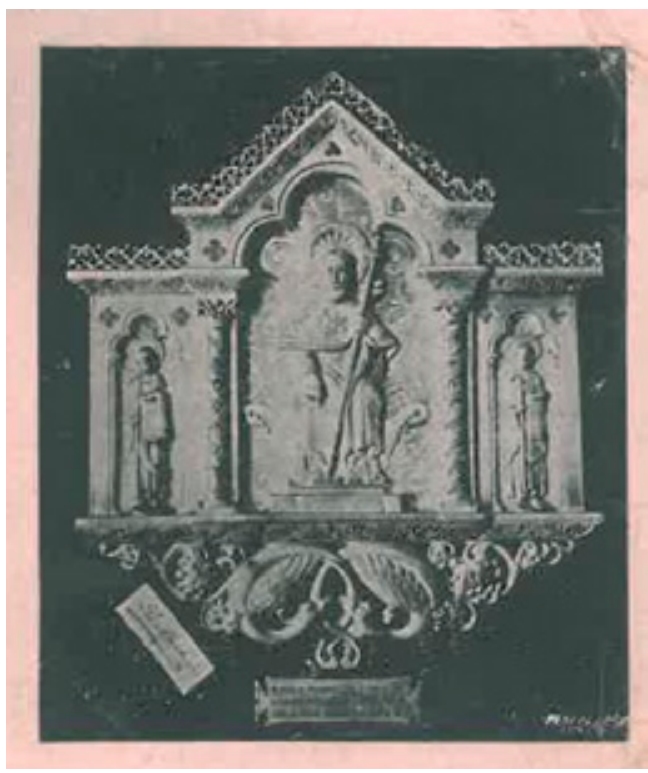

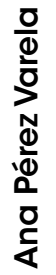

Fig. 8. Ricardo Martínez Costoya: Cuadro conmemorativo para Alfonso XIII, fotografía cedida por los hermanos de Diego Agudo, bisnietos de RMC

tográficas no permiten identificar la figuración. Hasta donde se puede apreciar, las ocho cartelas del borde parecen cubrirse con putti o figuras de corte alegórico separadas por máscaras muy teatrales, alternando con lo que parecen ser grutescos. Una ancha cenefa vegetal acoge un medallón con una escena que apenas alcanzamos a ver, en la que se pueden distinguir una barca, una posible Virgen con el niño y un Resucitado. El propio niño Jesús parece estar introduciendo el dedo en las llagas del costado de su versión adulta. Podríamos pensar en la Navis Institoris, o Nave que de lejos trae el pan, un tema de emblemática mariana que podría unir la bandeja con una función eucarística ${ }^{43}$. Sin embargo, en este emblema lo habitual es que aparezca Cristo bajo la iconografía de crucificado. Además, también contamos con una figura joven sentada en la popa y un anciano recostado sobre la proa. Proponer una interpretación iconográfica aproximada nos resulta por el momento imposible.

También gallonada, pero muy diferente, tenemos una bandeja con patrón ornamental concéntrico y simétrico. Creemos que esta bandeja es la misma expuesta como pieza central en la Exposición Regional de Lugo (1896) (fig. 2). De no ser 


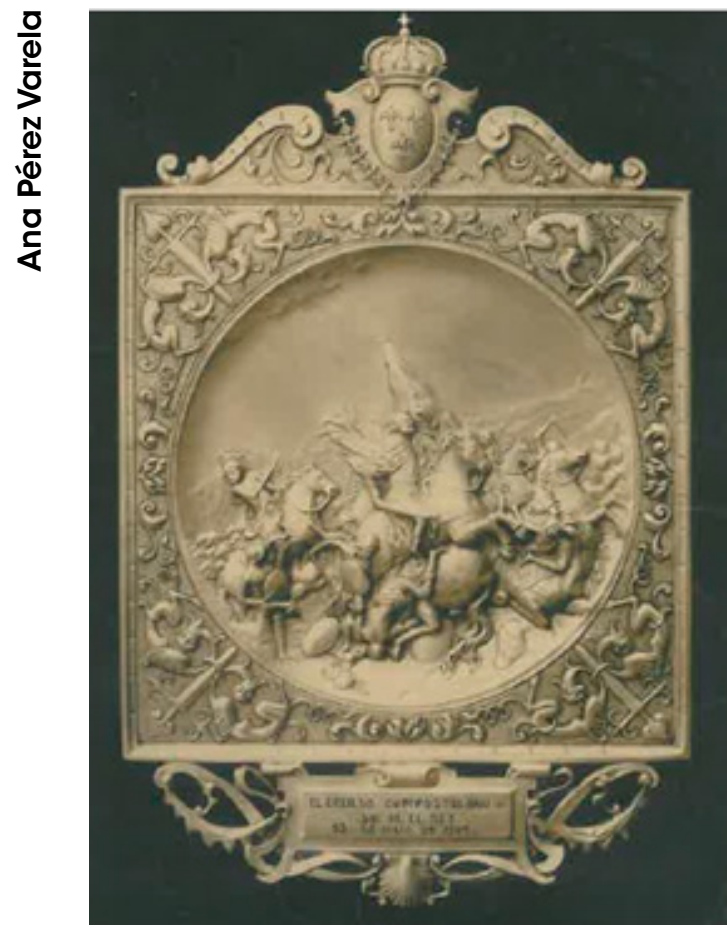

Fig. 9. Ricardo Martínez Costoya: Cuadro conmemorativo para Alfonso XIII, fotografía cedida por los hermanos de Diego Agudo, bisnietos de RMC

la misma pieza estaríamos hablando de un tipo idéntico repetido por el platero para su clientela.

Ya de forma rectangular, contamos con una bandeja, también publicada por Mira Leroy ${ }^{44}$, que ostenta una original decoración que cubre toda la superficie a base de una compartimentación en doce campos o cuarteles, adornados con patrones rococós de tallos, hojas, ramas, ces vegetales y rocalla. Tiene el borde dentado a base de troquelado, un recurso habitual en sus piezas. Como de otras anteriores, el platero conservaba varias fotografías de esta obra, y en sus reversos se pueden leer manuscritas distintas anotaciones relativas a precios y pesos.

Otra bandeja rectangular, pero de borde ondulado, presenta un asiento decorado con un bello patrón ornamental inciso de sabor art decó. Está formado por unos finos tallos o cintas que se extienden a lo largo de la bandeja entrelazándose en cada uno de los centros de cada lado. En el centro observamos un adorno que hasta donde nos permite observar la calidad de la fotografía,

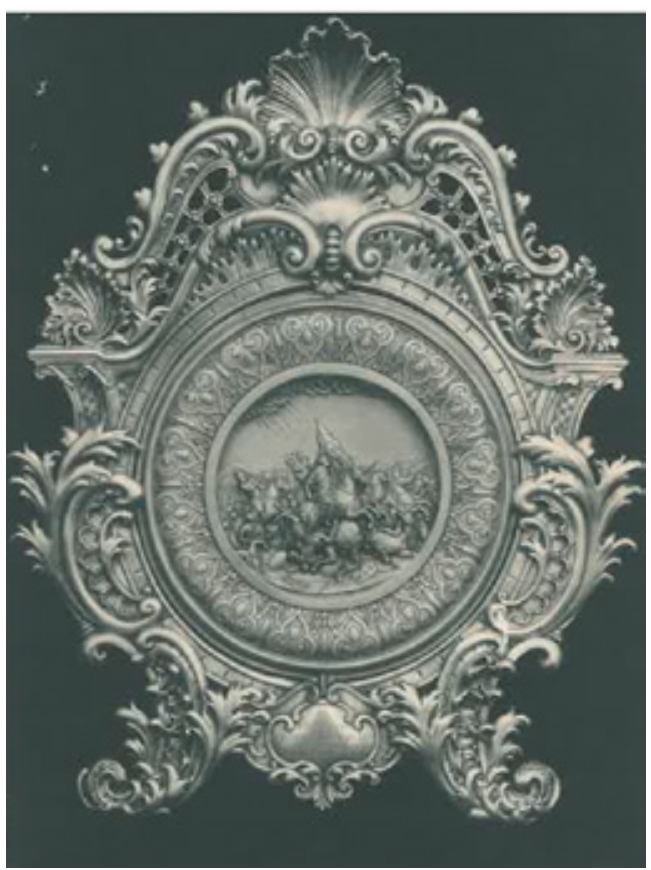

Fig. 10. Ricardo Martínez Costoya: Cuadro conmemorativo para Eugenio Montero Ríos, fotografía cedida por los hermanos de Diego Agudo, bisnietos de RMC

parecen dos iniciales que, al igual que en otras dos bandejas del platero, ostentan caracteres de raíz pseudogótica que debieron pertenecer a las iniciales del cliente.

También tenemos dos bandejas con asa. La primera es rectangular, con ancha orilla decorada de influencia rococó, asiento liso, y dos asas de estilo art decó. En el reverso de la fotografía, se pueden leer medidas y precio, y además: "Esta puede ser lisa con adorno con cenefa alrededor y asas", lo que nos habla de nuevo de una clientela que puede encargar obras al gusto. La segunda pieza con asas presenta una forma mixtilínea con orilla ancha formada por dos lados largos cóncavos y dos lados cortos convexos. Las asas se resuelven como un haz de tallos o cintas que se decoran en su parte central con una pequeña ova. La cenefa de la orilla se decora enteramente con el bello discurrir de vides, entrelazadas unas con otras, que dejan entrever racimos de uvas que salpican toda la superficie. Por este tipo de ornamentación podríamos plantearnos que se trate de una pieza con función eucarística. 


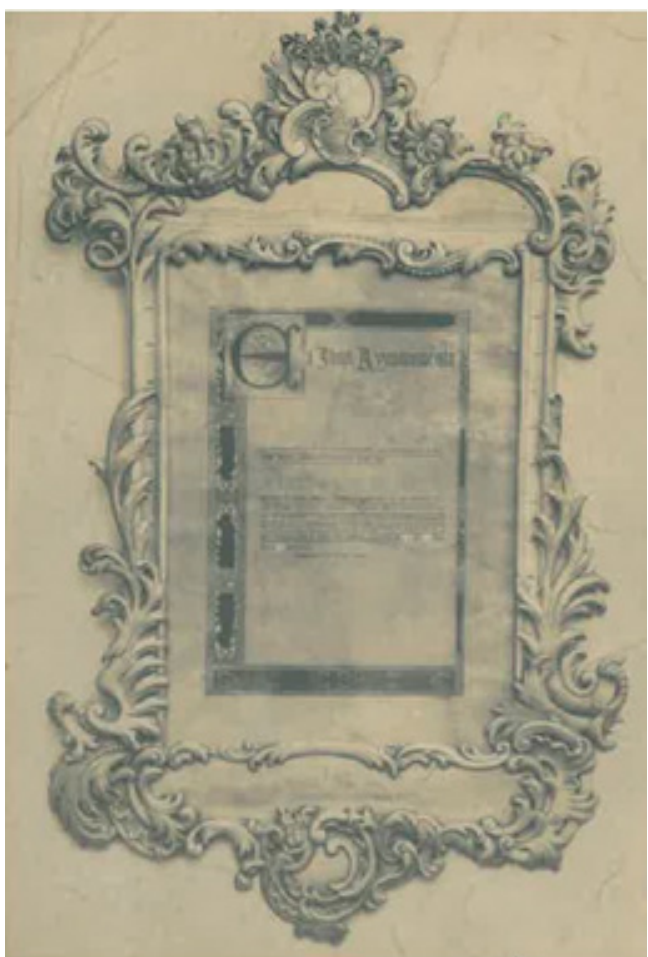

Fig. 11. Ricardo Martínez Costoya: Cuadro conmemorativo para Augusto Besada, fotografía cedida por los hermanos de Diego Agudo, bisnietos de RMC

Asimismo contamos con varios ejemplos de forma ovalada. La primera presenta decoración en toda su superficie, protagonizada por una guirnalda polimixtilínea de eses y ces entrelazadas que rematan en los extremos del eje largo en adornos de perfil conopial. El resto se cubre con un asiento romboidal picado de lustre -un patrón decorativo habitual en sus obras-, al que se superpone un óvalo en relieve con adorno central. Otra bandeja presenta un sabor todavía más rococó con borde mixtilíneo ondulado. Los adornos se corresponden con el mismo estilo, tanto la cenefa de la orilla como el gran adorno de rocalla asimétrica que cubre el asiento.

El segundo tipo ovalado está representado por una hermosa bandeja, publicada por Bouza Brey ${ }^{45}$, que reproduce un tipo habitual en el siglo XVIII, sin orilla, cubierto por un bello trabajo de ornamentación vegetal de figuras de tulipanes en toda la superficie, que se entrelazan con tallos y hojas de modo simétrico centrando un óvalo.

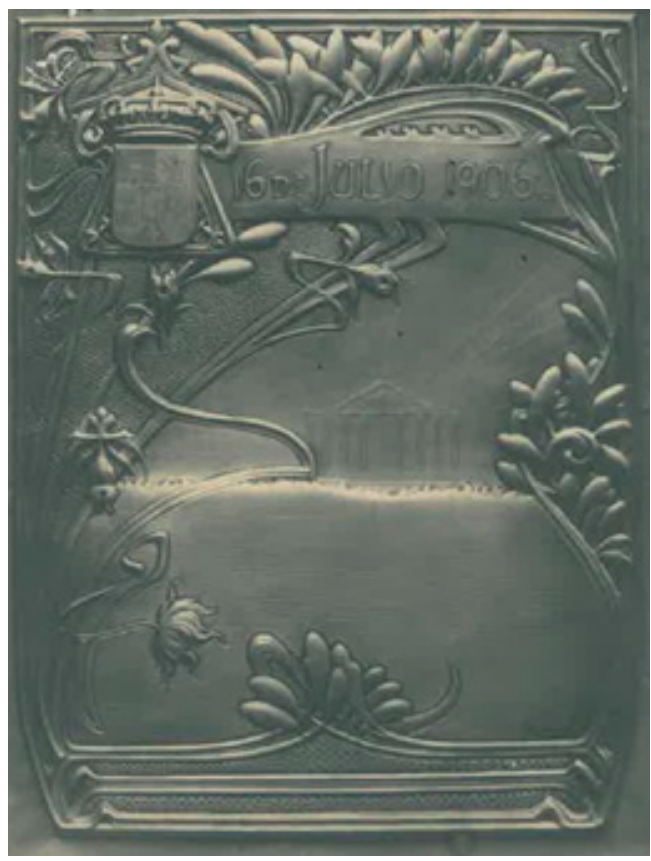

Fig. 12. Ricardo Martínez Costoya: Cuadro conmemorativo para Cleto Troncoso Pequeño, fotografía cedida por los hermanos de Diego Agudo, bisnietos de RMC

Repitió el mismo esquema formal y decorativo en otra pieza, también conocida por fotografía, pero sintetizando la decoración de forma esquemática. Este segundo modelo fue publicado por Mira Leroy ${ }^{46}$, y en el recorte conservado por Martínez se anotan de nuevo varias opciones de medidas.

El tercer tipo es el ovalado con lados cortos resaltados. En un primer ejemplo, esos extremos, lobulados, se convierten en dos partes para asirla, con un adorno muy plástico que semeja un gran fruto como una piña o una granada, en una solución estética que recuerda a piezas mexicanas. Más original resulta una bandeja art decó de perfil formado por una orilla ancha en los lados cortos, que adquiere un carácter apuntado, y orilla estrecha en los lados largos ${ }^{47}$. Todo el borde está recorrido por canales o estrías que en los lados cortos se entrelazan y complican en un adorno modernista, que deja intersticios calados, superponiéndose en una forma mixtilínea, con una especie de adorno que recuerda al penacho de un pavo real, o un ramillete de bolas con tallo en abanico. Conservamos el boceto preparatorio para esta bandeja, que nada varía en su forma 


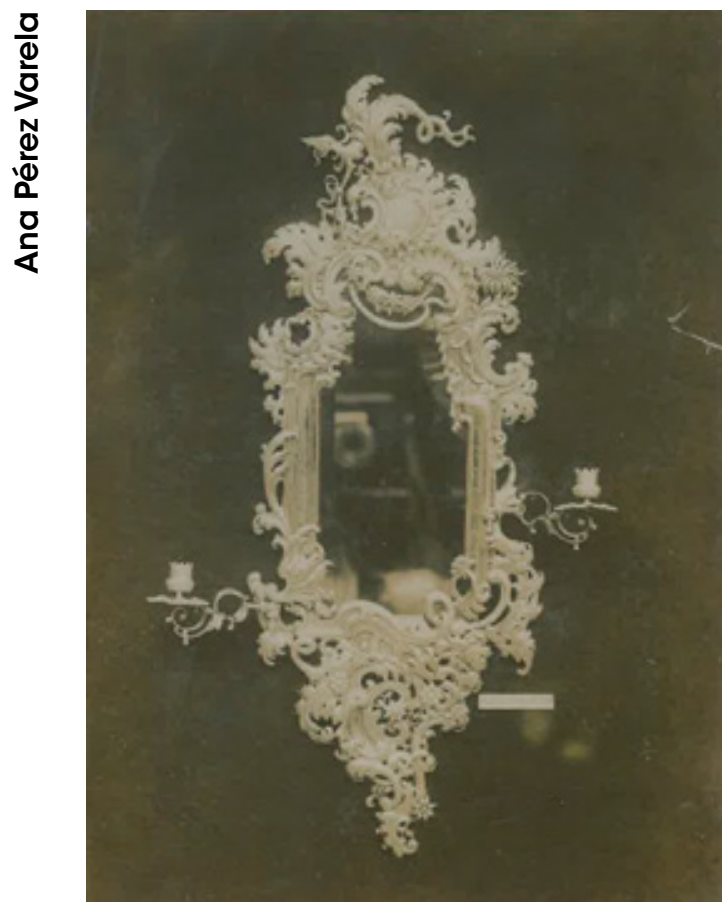

Fig. 13. Ricardo Martínez Costoya: Cornucopia, fotografía cedida por los hermanos de Diego Agudo, bisnietos de RMC

final, y también la vemos en el centro de su vitrina de la Exposición Regional Gallega (1909) (fig. 3).

Para terminar con sus bandejas tenemos un ejemplo marcadamente rococó, con orilla mixtilínea formada por ces de mayor y menor tamaño, enfrentadas en curva y contracurva, y animada con pequeños dentículos que sobresalen de su perímetro de forma asimétrica. Los adornos de rocalla y vegetación enroscada, flores, y ces sogueadas o nervadas se disponen sin orden o simetría por la estructura. El asiento se cubre con nervios dispuestos de forma concéntrica sin rectitud, dando aspecto de hoja escarolada.

\section{Placas conmemorativas}

Más interesante que las bandejas, resulta la aparición entre sus fotografías de más de una decena placas conmemorativas que están asociadas a personajes y momentos históricos de la ciudad de Santiago. En la prensa son abundantes las noticias alusivas a estas obras, y algunas nos han permitido identificar las piezas fotografiadas y sus destinatarios, entre los que encontramos a

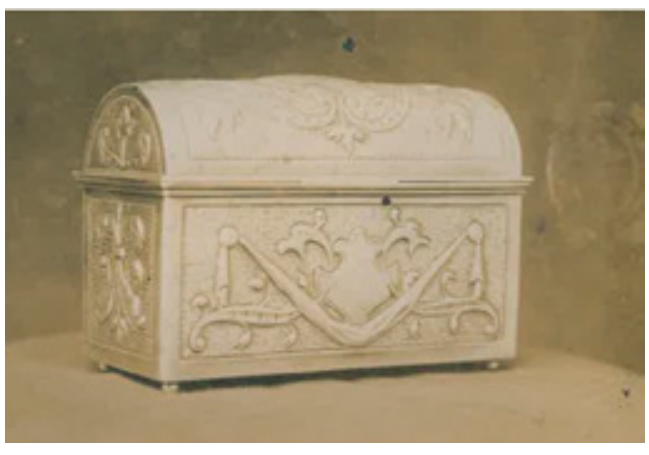

Fig. 14. Ricardo Martínez Costoya: Cofre, fotografía cedida por los hermanos de Diego Agudo, bisnietos de RMC

figuras ilustres de la historia del tránsito del siglo XIX al XX en Compostela.

En orden cronológico, en primer lugar contamos con un ejemplo que presenta a un elegante Santiago peregrino bajo una exquisita arquitectura renacentista adornada con motivos a candelieri. Creemos que se corresponde con el premio obsequiado al ganador de una carrera de velocípedos en 1890, encargado por el arzobispo Martín de Herrera, y referido en prensa como "un cuadro artístico de plata repujada, bajo un doselete de gusto admirable y con la imagen del santo Apóstol"48. Copia literalmente la portada renacentista conocida como la antigua puerta a la capilla de las Reliquias en la catedral de Santiago (1521-1927), de Juan de Álava ${ }^{49}$, configurada a modo de arco de triunfo con frontón triangular.

Una de las placas más curiosas es un ejemplo que precisamente hemos podido identificar gracias a la prensa, que la describe profusamente (fig. 7). Se trata de una obra conjunta de Ricardo Martínez con el escultor Ángel Bar, el pintor Urbano González, y el herrero José Vilas, llevada a cabo en los talleres de nuestro platero en 1899. Consiste en un gran tablero de nogal al que se superpone una pantalla arquitectónica de plata compuesta por tres columnas a modo de pseudocariátides con figuras alegóricas en representación del Arte, la Ciencia y la Industria. Sobre su cabeza sostienen una gran cornisa rematada por una elegante crestería compuesta de bichas aladas y pináculos, abrazando "un escudo coronado que ostenta perfectamente enlazados los atributos de la carrera de ingenieros". De forma asimétrica, ciñen por un lado un medallón con 
busto, y por el otro un lienzo al óleo de Urbano González, que "dando una nueva prueba de su inagotable inspiración, ha representado con verdad de efecto de espacio y de perspectiva un puente de nuestras pintorescas rías". Según el periódico, "todo el trabajo de orfebrería, excepción hecha de las figuras [modeladas por Ángel Bar], consta de tres planchas, dato que acusa las dificultades con que tropezó el artista para el movido de las ménsulas y cornisas y para conservar las superficies planas". Pese a que la identidad del retratado en busto no se menciona, es obvio que se trata de un personaje relacionado con la industria. El periódico apunta: "[Ricardo Martínez] ofrecerá una vez más ocasión de que en la corte de España se aprecie el justo renombre de que gozan los artistas compostelanos", por lo que sabemos que el destinatario residía en Madrid ${ }^{50}$.

También hemos hallado las fotografías de los dos cuadros que le encargó el cabildo catedralicio para agradecer la visita del monarca Alfonso XIII en los años santos de 1904 y 1909. El primero de ellos (fig. 8) consiste en un modelo muy repetido en su trayectoria. Los periódicos reprodujeron la misma fotografía que hemos hallado en su archivo, además de indicarnos las medidas $^{51}$ y el precio, de 2.000 pesetas $^{52}$. La prensa se refiere al cuadro como un "primer cuerpo del altar mayor [...] [con] la imagen del apóstol Santiago como aparece en el citado altar" ${ }^{53}$. En realidad, este modelo consiste, efectivamente, en una representación de Santiago a imagen de la estatua del altar mayor, pero acogido por una arquitectura neorrománica confeccionada en base a tres estancias articuladas con un arco trilobulado. La central, de mayor tamaño, se cubre con un remate triangular y las laterales con arquitrabe recto, siendo las tres recorridas por una fina crestería. Se trata de un esquema de arcadas-hornacina acogiendo figuras -la central al referido Apóstol, las laterales, a sus discípulos Teodoro y Atanasio-, totalmente deudora del enterramiento apostólico. Como ya hemos apuntado, la urna de los restos de Santiago constituyó una sombra estilística continua en su producción. Conocemos este modelo para Alfonso XIII idéntico en dos pilas de agua bendita en colección particular, y fue ensayado por

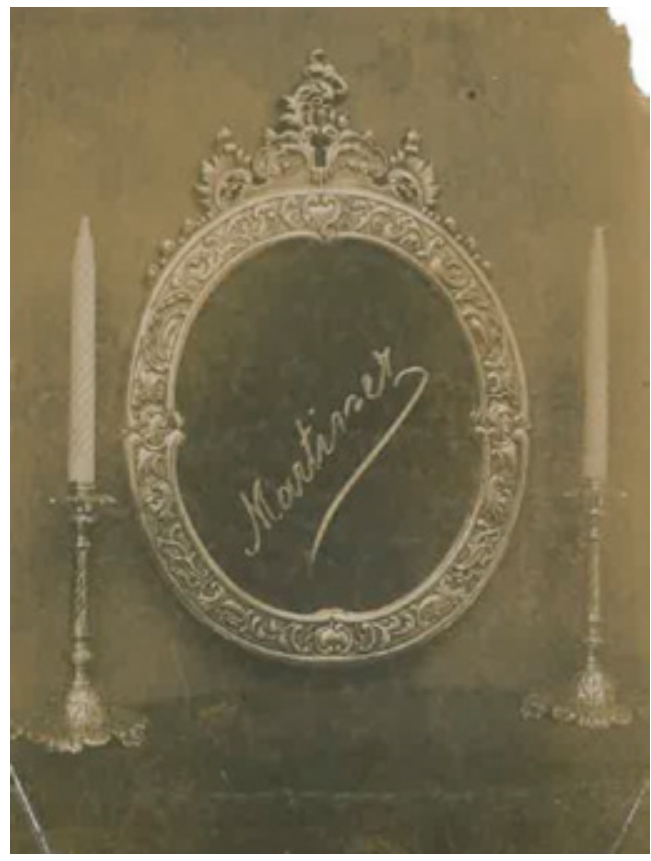

Fig. 15. Ricardo Martínez Costoya: Conjunto de espejo y candeleros, fotografía cedida por los hermanos de Diego Agudo, bisnietos de RMC

el platero en varios bocetos conservados en su archivo.

La prensa también reproduce el ejemplar de 1909 (fig. 9), compuesto como un relieve circular de la batalla de Clavijo ${ }^{54}$. Este molde fue empleado por Martínez en múltiples ocasiones, habitualmente aprovechado para llevar a cabo los cuadros de ofrenda que se entregaban a las autoridades cuando venían a hacer la ofrenda al Apóstol el día de su festividad55. Se trata de un modelo iconográfico tomado literalmente del tímpano pétreo del pazo de Raxoi, construido por José Ferreiro sobre diseños de Gregorio Ferro ${ }^{56}$. La composición es idéntica, adoptando la forma triangular del marco arquitectónico realizado en el edificio. Las figuras repiten posturas y posiciones, con el caballo de Santiago en corveta y el Apóstol enarbolando la bandera que actúa de vértice compositivo, bajo el cual se articula una masa de guerreros. En el caso de la pieza para Alfonso XIII, la escena se enmarca en un marco cuadrado decorado a candelieri con cruces de Santiago en las esquinas. Un remate rococó cierra la parte superior flanqueando el escudo, y un ca- 
lado de tipo modernista como una cinta dentada que se enrosca sobre sí misma, ciñe la pieza por debajo, rodeando una cartela sobre una vieira donde se lee: "El cabildo compostelano a / S. M. el Rey /13 de julio de 1909".

Fue uno de sus modelos más repetidos, a juzgar por las noticias de prensa que hacen referencia a los mismos. El ejemplar más sobresaliente con este molde iconográfico es un cuadro rectangular de 110 centímetros de ancho por 74 de alto, que se conserva en la catedral de Santiago, anónimo, y que nosotros creemos que puede ser obra de Martínez ${ }^{57}$. En su archivo también hemos hallado dos ejemplos del molde en plato redondo, con ancha orilla decorada por una greca modernista. Uno de ellos aparece en la fotografía del conjunto de vajilla (fig. 1). Otro (fig. 10), se encaja dentro de un espectacular marco rococó, compuesto por numerosas ces de carácter vegetal que se enroscan y enfrentan en curva y contracurva ramificándose en hojas de acanto, cenefas de pétalos, dentículos y hojas rizadas de aspecto avenerado, en especial el gran remate con su típica hoja-concha, que hemos tenido oportunidad de ver idéntico en dos de sus pilas de agua bendita. Sabemos que uno de estos relieves de Clavijo fue entregado a Eugenio Montero Ríos en 1910, en un "artístico marco de plata repujado" de cincuenta centímetros, que incorporaba una dedicatoria en la parte inferior ${ }^{58}$. Aunque no alcanzamos a leer la inscripción, creemos que se trata de esta pieza fotografiada. No tenemos dudas de que el platero debió querer conservar una representación de una pieza encargada para tan distinguido político.

En 1908 se le encargó la obra para el homenaje que la Liga de Amigos le profesó al señor José Rodríguez Carracido (1856-1928) ${ }^{59}$. Consiste en una placa rectangular con remate superior triangular, con laterales decorados a base de dos plásticas columnas torsas vegetales recorridas por un tallo floreado que las ciñe en espiral. Está protagonizada por una figura alegórica sentada, tocada con laurel, y con una antorcha en la mano izquierda, dirigida hacia el cielo. En el fondo vemos lo que podría interpretarse como la fachada de la Universidad, teniendo en cuenta que el homenajeado fue catedrático de bioquímica60.

En el mismo año de 1908 realizó dos obras entregadas a Augusto González Besada (1865-
1919)61, consistentes en dos grandes marcos para sendos diplomas que le otorgaron el ayuntamiento de Cambados y la diputación de Pontevedra, con el fin de nombrarlo hijo adoptivo. La prensa menciona uno de ellos (fig. 11) 62 $^{6}$ como un "marco estilo Luis XVI", con el escudo consistorial y dos vistas del puerto de Cambados antes y después de las obras patrocinadas por Besada, dos dibujos del artista pontevedrés Sanmartín. Este último detalle apenas es perceptible en la fotografía, pero puede intuirse.

Por último, en 1912 llevó a cabo una placa entregada por el regimiento de infantería de Zaragoza número 12 a la comunidad de padres franciscanos, en gratitud por haber celebrado en su convento un acto fúnebre en honor de los fallecidos en servicio en Melilla en la guerra contra Marruecos. Se trata de una plancha polimixtilínea compuesta por tres secciones separadas por columnas alargadas de tipo periforme, que arrancan de un original motivo de raíces de árbol, y rematan en floridos jarrones con un hacha. La parte central se enmarca por dos grandes palmas cruzadas entrelazadas en una cruz de Santiago.

\section{cubiertas de libros}

Una de las obras fotografiadas (fig. 12) se corresponde con un obsequio al señor Cleto Troncoso Pequeño, destacado político compostelano, al ser nombrado rector de la Universidad de Santiago en $1906^{63}$. La plancha, que a primera vista podía parecer un cuadro conmemorativo, fue realmente empleada para adornar la portada de un álbum fotográfico. Fue descrita en prensa como una pieza elegante y modernista ${ }^{64}$, y consiste en una placa de plata rectangular, enmarcada por un fino entrelazado de tallos art decó asimétricos, centrando una imagen, apenas incisa, de la fachada de la Universidad, hoy facultad de Geografía e Historia. Fue expuesto en la muestra de 1909 (fig. 3).

Entre sus fotografías aparece otro libro. Su cubierta está compuesta por una elegante encuadernación de cuero formando un campo de rombos que alternan cenefas de flores de lis y estrellas, un tipo de adorno muy empleado en las obras de Martínez -sin ir más lejos, al fondo de la urna apostólica. Los esquinales se resuelven de forma triangular, compuestos por animadas ces rococós en curva y contracurva. En el centro, apa- 
rece el escudo con el Toisón de Oro pendiendo. Hemos identificado esta obra como la referida en prensa para regalar a Alfonso XIII. Se trata de un libro realizado por el encuadernador pontevedrés Micó, para contener el expediente de posesión de la isla de Cortegada, que fue donada al monarca por los vecinos para construir una residencia de verano que nunca llegó a materializarse ${ }^{65}$.

\section{Cornucopias}

Además de bandejas y placas, contamos con fotografías de otras tipologías de las cuales resulta complicado encontrar ejemplos en la platería gallega, entre las que destaca la cornucopia, un tipo del que se conoce un número mínimo de ejemplos en toda Europa. Consiste en un gran marco decorativo, que ciñe espejos o escenas iconográficas, del que parten dos brazos con candelero en el que encajan las velas. Creemos que el platero conocía este tipo gracias a la magnífica pareja de cornucopias augsburguesas que envió la reina madre Mariana de Austria como ofrenda al apóstol Santiago en $1683^{66}$. Sabemos que Martínez intervino en estas piezas arreglándolas por lo menos en una ocasión, por lo que tuvo pleno conocimiento de su estructura ${ }^{67}$. Hasta la fecha, no conocemos otras piezas similares en España68.

Ricardo Martínez empleó este tipo en una obra muy significativa que conocemos gracias a una de sus fotografías, y mejor aún debido a la descripción detallada de la pieza en la prensa. Se trata de una cornucopia que la diputación de $\mathrm{A}$ Coruña encargó al platero para regalar al exministro de justicia Eduardo Dato. Consiste en un gran marco vegetal que ciñe un espejo vertical, y remata en una bicha alada con cola enroscada de la que prenden guirnaldas con las iniciales del ministro. Además, incorporó dos candeleros a distintas alturas, subrayando la asimetría rococó que está impresa en toda la pieza69 (fig. 13).

\section{Cofres, candelabros y candeleros}

Conservamos dos fotografías de cofres (fig. 14) que parecen seguir el tipo de aquéllos que servían para guardar las llaves de sagrario, de los cuales tenemos constancia documental como encargos para la Catedral ${ }^{70}$, aunque no sabemos si se corresponden con éstos. No presentan iconografía sacra sino una compartimentación de paneles de grutescos que recuerdan a los em- pleados en los pedestales de su figura Santiago premiada en Lugo, ya mencionada. Presentan la misma caja de prisma rectangular, apoyada en pequeñas patitas, y una tapa de medio cilindro que encaja sobre una cornisa. También han llegado hasta nosotros los bocetos preparatorios que ensayan los elementos ornamentales. De estar ante piezas de platería civil probablemente se trate de joyeros.

Los dos ejemplos de candelabro presentan una estructura similar, con cuatro brazos desplegados en las cuatro direcciones y uno central. Sin embargo, su morfología es bien distinta. El primero, de estilo Imperio, ostenta un pie de pirámide de base cuadrada, cuerpo de fuste acanalado y sencillos brazos en ese con mecheros ovoides. El segundo, más barroco, presenta un pie troncocónico, fuste periforme con panza, y brazos muy originales formados en base a un grifo alado con alas explayadas, cuya cola se enrosca en una estrella.

Por último, un candelero que en realidad está pensado para encajar una bombilla de luz eléctrica, presenta figuración antropomórfica exenta en una figurilla de un amorcillo o incluso un Cupido, sobre pedestal troncocónico, del que arranca un gran tallo curvo cuya flor abierta acoge la bombilla. Tanto el último de sus candelabros como esta pieza fueron incluidos por Mira Leroy en su publicación francesa ${ }^{71}$.

Otras piezas: espejos, juegos de tocador, juegos de café, y guardacartas

Conservamos una fotografía de un juego de candeleros y espejo (fig. 15), anotado como para colgar de la pared o para reposar sobre una mesa. En la fotografía aparece colgado y creemos que es el mismo que se encuentra apoyado sobre una repisa en la exposición de 1909 (fig. 3). En todo caso, se trata de un espejo ovalado, con paralelismos formales con sus bandejas y un remate de penacho rococó. Los candeleros son sencillos, con pie troncocónico, cuerpo cilíndrico y corola para encajar la vela.

También hemos hallado un juego de tocador compuesto de una guarnición de un cepillo para el pelo, un estuche para peine, un bote de ungüento y un espejo ovalado con mango. Esta última pieza está ensayada de forma exacta en un boceto conservado. El tarro es pseudoesférico, con un pie 
que parece seguir su característico esquema en tres molduras -común a sus piezas sacras- y una tapa troncocónica campaniforme. Todo el conjunto está decorado con un patrón vegetal rococó.

Entre las piezas de vajilla de Ricardo Martínez conocemos dos juegos de café, ambos con bandeja. Las jarritas siguen tipos similares a sus vinajeras para Santa María Salomé ${ }^{72}$, con un cuerpo redondeado y asas en ce. Las bandejas son ovaladas con orilla decorada, habituales en su catálogo.

Por último, una fotografía presenta una obra que por su morfología parece ser un guardacartas, compuesto por dos placas unidas por una base con patas. El frente presenta una vista de la fachada del Seminario, antiguo monasterio de San Martiño Pinario, ceñido por grutescos. La estructura trasera, de estilo art decó, se compone a modo de dos esbeltos tallos retorcidos rematados en flor campaniforme. Se trata de una inusual pieza de orfebrería civil de la cual no hemos hallado más ejemplos en la platería gallega.

\section{Conclusión}

No creemos equivocarnos si afirmamos que Ricardo Martínez Costoya constituye una de las figuras artísticas más importantes en la Compostela de las últimas décadas del siglo XIX y las primeras del XX. El afortunado hallazgo de su archivo nos ha permitido conocer una extraordinaria cantidad de piezas de platería civil de la época, muy escasas en Galicia, especialmente en las colecciones accesibles al público. Estas obras nos hablan de los usos y costumbres de la sociedad compostelana burguesa, que quería contar entre sus ajuares con las piezas del más afamado orfebre de la época.

A su obrador debieron acudir a encargar piezas gran cantidad de santiagueses, que seguramente tuvieron a su disposición, además de las piezas de muestra, las fotografías sacadas por el propio platero que le permitían confeccionar una especie de catálogo. Las fotografías suponen una fuente de información muy valiosa para llevar a cabo conclusiones sobre los precios de las piezas en la época. La principal fuente de análisis del precio de la onza de plata y las hechuras lo constituyen los encargos eclesiásticos, reflejados en la documentación parroquial y especialmente el Archivo de la Catedral de Santiago. Por consi- guiente, es muy complicado hallar datos sobre el valor de las piezas de platería civil en el momento de la compra, para lo cual este archivo constituye una fuente excepcional.

El hecho de que se repitan insistentemente algunos tipos, como las bandejas redondas y ovaladas; los platos de orilla decorada o los de asiento con escenas iconográficas; las placas conmemorativas; las piezas de vajilla; o los espejos; nos da a entender que fueron piezas muy demandadas por la clientela civil y que el platero empleó unos modelos estructurales similares que variaba especialmente en patrones decorativos y estilísticos.

Su relación con los encargos más importantes de la Catedral y el Ayuntamiento lo llevó a participar en algunos de los hitos históricos más relevantes de la Compostela de la época, realizando obras para personajes tan distinguidos como el cardenal Martín de Herrera, Eugenio Montero Ríos, Augusto González Besada, Máximo de la Riva, Cleto Troncoso; además de algunos ministros, militares, o el propio Alfonso XIII. Estas placas son especialmente interesantes porque a través de las obras de arte, somos capaces de reconstruir el contexto histórico institucional de la Compostela del cambio de siglo, reflexionando sobre el papel que jugó la platería como insignia de los homenajes y actos conmemorativos, y el intercambio de regalos diplomáticos.

Su obra no sólo refleja, a través de sus tipologías, las piezas demandadas por la sociedad civil, sino también, a través de su estilo, del gusto artístico de la época. Fuertemente marcado por el influjo autóctono, en su catálogo no faltan elementos de iconografía jacobea o referencias literales a la arquitectura compostelana. Sin embargo, en conjunto, sus obras aspiran a seguir la moda internacional de la época. Su catálogo, de excepcional variedad, juega con todos los estilos históricos para construir piezas en la que predominan las influencias neogóticas y modernistas, propias del contexto artístico europeo en la cronología en la que ejerció su carrera profesional. Ricardo Martínez Costoya, hasta ahora sólo conocido por una pequeña cantidad de obras sacras, se revela de este modo, como el mejor artífice para estudiar los gustos de la platería civil en el tránsito del siglo XIX al XX en Santiago de Compostela. 


\section{NOTAS}

* Para la realización de este estudio se ha contado con la financiación del Ministerio de Educación del gobierno de España a través de una ayuda de Formación de Profesorado Universitario (FPU), así como de los proyectos: Historia del arte, innovación y nuevas tecnologías: El patrimonio monástico y conventual gallego. De la reforma de los Reyes Católicos a la Exclaustración. EXCELENCIA 2016 (HAR201676097-P, 30/12/2016-29/12/2019); y Consolidacaión e estruturación. REDES 2016 Gl-1907 IACOBUS. Patrimonio cultural. Servizos Históricos e Técnicos (R2016/023, 01/01/2017-31/12/2018).

1 Fue el único hijo del matrimonio entre Josefa Costoya y José Martínez Lista. Archivo Histórico Universitario de Santiago (AHUS). Rexistro civil. Rexistro de Bautizados, 1859 (AM 753), rexistro 858.

2 Desconocemos la relación entre José Losada y la familia de Martínez, pero sabemos que en todo caso fue anterior al nacimiento de Ricardo, ya que éste fue apadrinado por Benigno y Concepción, hijos de Losada. Archivo Histórico Diocesano de Santiago (AHDS). Santiago. San Miguel dos Agros. Libros sacramentales. Bautizados. 1857-1860, leg. 15.

3 Sobre José Losada, ver: Pérez Varela, Ana. 2016. "Obras de José Losada en la colección de platería de la catedral de Santiago de Compostela. Fuentes para su estudio y análisis de las piezas." In Estudios de platería San Eloy, edited by Jesús Rivas Carmona, 505-522. Murcia: Universidad de Murcia.

4 Éstas son unas plantillas prediseñadas encabezadas por un membrete o logotipo artístico. Contamos con hasta tres modelos diferentes, rastreables en las facturas del archivo catedralicio. En el segundo y tercer tipo, empleados sucesivamente entre 1898-1900 y 19011903, podemos leer: "R. MARTINEZ / Platero de la Catedral / Sucesor de Losada / Orfebrería de Arte Cristiano / Calle de Fonseca / Santiago". El segundo modelo aparece en: Archivo de la Catedral de Santiago (ACS). Fábrica. Comprobantes de cuentas de Fábrica, 18971901 (IG 1018), separatas de "1898";
"1899"; "1900"; y Comprobantes de cuentas (CB 192), separata de "18991900". El tercer modelo aparece en: ACS. Fábrica. Comprobantes de cuentas de Fábrica, 1897-1901, (IG 1018), separata de: "1901"; Comprobantes de cuentas (CB 194), separatas de "1901"; y"1902"; y "1903".

5 La expedición organizada por el cardenal Miguel Payá y Rico (18741886) y dirigida por los canónigos López Ferreiro y Labín Cabello, dio sus frutos al toparse, en 1879, con los cimientos del edículo sepulcral romano y un osario con los restos de tres esqueletos humanos, que, tras pasar un proceso canónico de autentificación, fueron declarados los legítimos restos de Santiago el Mayor y sus dos discípulos, Teodoro y Atanasio, mediante la bula Deus Omnipotens (1884) del pontífice León XIII. Al cristalizar tan esperado hallazgo, las peregrinaciones sufrieron un proceso de reactivación que resultó en una visible mejora de la situación económica de la fábrica, que comenzó a patrocinar obras artísticas acordes con el contexto, entre las que cabe destacar la gran reconstrucción de la cripta. Pérez Varela, Ana. 2017. "Una tumba para el Hijo del Trueno: La Remodelación Decimonónica de la cripta de la catedral de Santiago y la urna argéntea de sus restos." In Genius Loci: Lugares e Significados. Places and Meanings, edited by Lucía Rosas, Ana Cristina Sousa, y Hugo Barreira, vol. 1, 319-329. Porto: CITCEM.

6 López Ferreiro, Antonio. 1891. Altar y cripta del apóstol Santiago, reseña histórica desde su origen hasta nuestros días. Santiago de Compostela: Imp. y Enc. del Seminario Conciliar Central, 32-33.

7 Pueden comprobarse en los siguientes documentos: ACS. Fábrica. Libro diario. 1886 (IG 56); 1887 (IG 61); 1888 (IG 62); 1889 (IG 63); 1890 (IG 64); 1891 (IG 65); 1892 (IG 66); 1893 (IG 67); 1894 (IG 68); 1895 (IG 69); 1896 (IG 70); 1897 (IG 71); y 1899 (IG 72). Hemos cotejado esta información con las matrículas industriales y de comercio que custodia el AHUS. En estos documentos, aparece señalada su tienda como "en la calle Fonseca" de 1887 a 1892. De 1893 a 1900 aparece ubicada como en "los bajos de la Catedral". De 1901 a 1924, vuelve a aparecer ubi- cado "en la calle Fonseca". No obstante, los documentos se refieren siempre al mismo local pese a las dos denominaciones. AHUS. Matrícula Industrial e de Comercio. Documentos de 1887 (AM 1760) a 1924 (AM 1793).

8 Según la documentación del manicomio de Conxo, José Losada ingresó en esta institución en marzo de 1886, y murió en febrero de 1887. AHDS. Fondo del Manicomio de Conxo. Libro Xeral de entrada/saída de enfermos (Libro de Alienados), 1885-1896, $\sin \mathrm{f}$.

9 La oficialidad del cargo es una cuestión difícil de esclarecer, ya que no se recoge en la documentación catedralicia como un nombramiento. Desconocemos si existía algún tipo de obligación contractual, aunque debido a toda la documentación que hemos manejado, creemos que el platero oficial debía, simplemente, cumplir con los encargos de la fábrica mientras se seguía dedicando a su labor comercial en su tienda-obrador. Durante la primera mitad del siglo XIX, el cargo fue inestable, y se pasó de platero a platero sin periodicidad concreta ni relación endogámica. En la segunda mitad del siglo, José Losada y Ricardo Martínez ostentan el cargo de forma vitalicia y estable.

10 Los documentos más interesantes para estudiar sus trabajos para la Catedral son los comprobantes de cuentas. Éstos registran los trabajos realizados cada año o cada semestre y la cantidad que se le paga por cada uno de ellos. También aparecen en algunos casos recibos sueltos por una obra concreta. Encontramos facturas emitidas a nombre de Ricardo Martínez de 1886 a 1924. ACS. Serie: Comprobantes de Cuentas.

11 Fernández Casanova, María del Carmen. 1982. "La Exposición regional de Santiago en 1858." Revista de Historia Contemporánea, 1, 108.

12 Anónimo. 1892. Catálogo de la Exposición de Industrias Artísticas de Barcelona. Barcelona: Henrich y Cia, 45.

${ }^{13}$ Conocimos esta pieza gracias a un recorte guardado por el propio platero, publicado en: Leroy, Mira. 1908. Matériaux et documents d'art spagnol. Barcelona: Librería Perera, lámina 42. 
14 Anónimo. 1896. Crónica del II Congreso Eucarístico Español, celebrado en Lugo en agosto de 1896. Lugo: Establecimiento tipográfico de G. Castro Montoya, 643.

15 Anónimo. 1897. Exposición Regional de Lugo. 1896. Catálogo general de expositores y premios adjudicados, resultado de los juegos florales y certámenes musicales. Lugo: Imprenta de Juan A. Menéndez, 80.

${ }^{16}$ En relación con la Exposición, su nombre aparece mencionado en diversos periódicos en más de un centenar de ocasiones. También lo encontramos en los documentos relativos a la exposición: Archivo do Museo do Pobo Galego (AMPG). Colección Blanco-Cicerón. Acta de Constitución da Sección de Arqueoloxía; Reglamento General de la Exposición Regional Gallega que ha de celebrarse en la ciudad de Santiago en el Año Santo de 1909, 28; y Boletín de la Exposición Regional de 1909, Santiago, 15 de julio de 1908, no 1, 2; septiembre de 1908, no 2, 2-3; y noviembre de 1909, no 3, 5.

17 Su muerte aparece reseñada en: El Compostelano, 29 de septiembre de 1927, 2-3; 30 de septiembre de 1927 , 2; y 2 de noviembre de 1927, 2; El Orzán, 1 de octubre de 1927, 2; El Pueblo Gallego, 1 de octubre de 1927, 13; y El Eco de Santiago, 20 de septiembre de 1927, 2.

18 Nos gustaría manifestar nuestro más sincero agradecimiento a los hermanos de Diego Agudo, bisnietos de Ricardo Martínez Costoya, el haber puesto a nuestra disposición el valioso archivo del platero; y todo el interés mostrado por su estudio y difusión, cediéndonos así mismo las fotografías para su reproducción. En especial, nos gustaría mencionar a Rosario de Diego, por las molestias que hubo de ocasionarle preparar todo el material para que pudiésemos tenerlo en soporte digital, además de contestar a nuestras continuas preguntas.

19 Su familia conserva la carta que Ricardo Martínez envió a sus futuros consuegros con motivo de la boda de su hija Isabel con Andrés de Diego, un reconocido médico santanderino.

20 Entre ellas contamos dos pilas de agua bendita propias; un cenicero conmemorativo de la Exposición Regional de 1909, que hemos certificado del platero gracias a la prensa de la época que reseña la pieza (Diario de Galicia, 16 de julio de 1913, 1; El Correo de Galicia, 14 de julio de 1913, 2; y El Eco de Santiago, 14 de julio de 1913, 2); y la medalla que le entregó el jurado del II Congreso Eucarístico de Lugo.

21 Sobre esta pieza, véase: Louzao Martínez, Francisco Xabier. 1993. "Doña María Ana de Neoburgo en Galicia: la arqueta eucarística y el ostensorio de la Real e Insigne Colegiata de Santa María del Campo de la Coruña." Historia 16, 201, 91-104; y Louzao Martínez, Francisco Xabier. 1993. Catálogo del Museo de Arte Sacro de La Coruña. Barcelona: Dúplex, 44.

22 La influencia de este patrón decorativo es especialmente notable en el diseño de una lámpara conocida por uno de los bocetos de su archivo, que no sabemos si llegó a realizarse. El modelo es un recorte de una lámina de: Leroy, Mira. 1905. Materiales y documentos del arte español, lámina 28.

${ }^{23}$ Se trata de las custodias de las parroquias de Ejulve y Tronchón. Según la publicación cuya hoja conservaba el platero, la primera presenta punzón barcelonés y data de principios del siglo XVI. La segunda está marcada en Morella y es de la primera mitad del siglo XV. La segunda se indica como esmaltada y de gran calidad artística. No hemos sido capaces de identificar a qué publicación pertenece la hoja.

${ }^{24}$ Pérez Varela, Ana. 2016. "Obras de José... op. cit., 519-521.

25 Este grabado fue realizado dentro del contexto de redescubrimiento y revalorización del pórtico del maestro Mateo en el contexto del revival medieval de la segunda mitad del siglo XIX, el desarrollo de la literatura de viajes, y el vaciado en yeso que realizó de la obra el South Kensington Museum de Londres, actual Victoria and Albert Museum. Sobre esta serie de grabados, con bibliografía actualizada, ver: Yzquierdo Peiró, Ramón. 2017. Los tesoros de la catedral de Santiago de Compostela. Santiago de Compostela: Consorcio de SantiagoTeófilo Edicións, 271.

${ }^{26}$ Los libros de modelos o pasantías de algunas zonas de España, em- pleados en los exámenes gremiales, han sido analizados en los siguientes estudios: Dalmases Balañá, Nuria. 1977. "La orfebrería barcelonesa del s. XVI a través de los Libres de Passanties." D'art, Revista del Departament d'historia de I'arte, 3-4, 5-30; Sanz Serrano, María Jesús. 1986. Antiguos dibujos de la platería sevillana. Sevilla: Diputación Provincial de Sevilla; García Gaínza, María Concepción. 1991. "El libro de Exámenes de Plateros." Goya, 225, 134141; García Gaínza, María Concepción. 1991. Dibujos antiguos de los plateros de Pamplona. Pamplona: Universidad de Navarra. Martín, Fernando. 2001. "Dibujos de platería en la Fundación Lázaro Galdiano." Goya, 285, 324-331; Cots Morató, Francisco de Paula. 2002. El examen de maestría en el arte de plateros de Valencia: los libros de dibujos y sus artífices. Valencia: Delegación de Cultura; Pérez Grande, Margarita. "Dibujos de examen de plateros de la ciudad de Granada (1735-1747)." Goya, 313-314, 257-270; y Méndez Hernán, Vicente. 2015. "Aprendices, oficiales, maestros plateros y dibujos de examen en el Madrid de finales del siglo XVIII y comienzos del XIX." In Estudios de platería San Eloy, edited by Jesús Rivas Carmona, 281-302. Murcia: Universidad de Murcia. En Galicia, sólo conocemos un estudio: Louzao Martínez, Francisco Xabier. 1991. "Dibujos de platería coruñesa." Goya, 221, 284-289.

27 Entre ellos, el más conocido en la época fue Manuel Chicharro Bisí, activo desde 1877. Acuña, Xosé Enrique y Cabo, José Luis. "La fotografía en Galicia." In Galicia Arte, tomo XVI: Arte Contemporáneo (II), edited by Francisco Rodríguez Iglesias, 488-505. A Coruña: Hércules.

28 Bouza Brey, Fermín. 1962. Platería civil compostelana hasta finales del siglo XIX. Santiago de Compostela: Seminario Padre Sarmiento de Estudios Gallegos.

29 Leroy, Mira. 1901-1906. Materiales y... op. cit.

30 Leroy, Mira. 1908. Matériaux et... op. cit.

31 Leroy, Mira. 1905-1906. Materiales y... op. cit., lámina 66 .

32 De Eduardo Rey se publica un bello báculo de estilo gótico, destinado 
al obispo electo de Mondoñedo, Juan José Solís. Leroy, Mira. 1905-1906. Materiales y... op. cit., lámina 70.

33 Esta estatua, conservada en la capilla de las Reliquias de la Catedral de Santiago, es una de las pocas piezas publicadas del platero hasta la fecha. Fue premiada en la Exposición Regional de Lugo (1896) y adquirida por la Catedral debido al éxito que cosechó en la muestra, tal y como transparentan las actas capitulares del cabildo. Pérez Varela, Ana. 2017. "Piezas de Ricardo Martínez Costoya en la colección de platería de la catedral de Santiago de Compostela." In Del taller al museo. Estudios sobre historia del arte, patrimonio y museología en Galicia, edited by Rosa Margarita Cacheda Barreiro \& Carla Fernández Martínez, 276-297. Santiago de Compostela: Andavira, 282-284.

34 Esta fotografía pertenece a un recorte de: Leroy, Mira. 1908. Matériaux et... op. cit., lámina 42.

${ }^{35}$ Alcalá Subastas. 2013. Catálogo de Alcalá Subastas, Madrid, 3 de diciembre, lote 363.

36 Leroy, Mira. 1908. Matériaux et... op. cit., lámina 17 .

37 Leroy, Mira. 1908. Matériaux et... op. cit., lámina 66 .

${ }^{38}$ El Eco de Santiago, 26 de octubre de 1904, 2 .

39 Ibídem, 23 de mayo de 1897, 2.

40 Ibídem, 27 de mayo de 1899, 2-3.

41 Leroy, Mira. 1905-1906. Materiales $y$... op. cit., sin paginar.

42 Bouza Brey, Fermín. 1962. Op. cit., pp. 62-63.

43 Agradecemos a la doctora Carme López Calderón que nos sugiriese esta posible interpretación.

44 Leroy, Mira. 1905-1906. Materiales y... op. cit., lámina 66 .

45 Bouza Brey, Fermín. 1962. Op. cit., pp. 62-63.

46 Leroy, Mira. 1905-1906. Materiales y... op. cit., lámina 66 .

47 La forma es la misma que la de una bandeja de Martínez en colección particular, aunque esta segunda presenta una filiación todavía más medieval. Pérez Varela, Ana. 2015. "Vida y obra del platero compostelano Ricardo Mar- tínez Costoya." Tesis de licenciatura, Universidad de Santiago de Compostela, 93.

${ }^{48}$ En el periódico se indica que llevará —en futuro- un marco de ébano. En la imagen creemos estar ante la parte de plata todavía exenta sin acoplar a la placa lígnea. Gaceta de Galicia, 16 de junio de 1890, 2.

49 Sobre esta obra, ver: Vila Jato, María Dolores. 1993. "A arquitectura." In Galicia Arte, Tomo XII: Galicia na época do Renacemento edited by María Dolores Vila Jato y José Manuel García Iglesias, 21-199. A Coruña: Hércules, 40-57.

50 El Eco de Santiago, 27 de mayo de 1899, 2-3. El artículo está firmado por Máximo de la Riva, industrial y político compostelano que sería elegido alcalde en 1922

51 Ibídem, 25 de julio de 1904, 4.

52 Gaceta de Galicia, 30 de julio de 1904, 3.

${ }^{53}$ El norte de Galicia, 2 de julio de 1904, 1.

${ }^{54}$ El Eco de Santiago, 27 de noviembre de 1909, 1.

55 Dentro de los encargos referidos en las facturas catedralicias, cabe señalar la gran cantidad de cuadros de ofrenda que se le encargan a lo largo de su carrera, que servían al intercambio de regalos diplomáticos con las personalidades nobiliarias y eclesiásticas que venían a presentar la ofrenda anual al Apóstol. Pérez Varela, Ana. 2015. "Vida y... op. cit., 27-28.

56 Sobre esta obra de José Ferreiro, ver: López Vázquez, José Manuel. 1993. "A escultura neoclásica." In Galicia Arte, Tomo XV: Arte Contemporánea (I), edited by José Manuel López Vázquez e lago Seara Morales, 28-85. A Coruña: Hércules. 92; y Otero Túñez, Ramón. 2004. "José Ferreiro." In Séculos XVIII e XIX, edited by Antón Pulido Novoa, 209-247. Vigo: Nova Galicia Edicións.

57 Para más información sobre la pieza, con bibliografía, ver: Yzquierdo Perrín, Ramón. 2017. Op. cit., 402. Para Ramón Yzquierdo, podría ser una obra de los Pecul, por relación familiar con José Gambino y José Ferreiro.

${ }^{58}$ Diario de Galicia, 27 de septiembre de 1910, 2 .
59 José Rodríguez Carracido fue un bioquímico y farmacéutico compostelano, pionero de la bioquímica en España y primer catedrático del país en su disciplina. Fue rector de la Universidad Central de Madrid, hoy Universidad Complutense.

60 Según la prensa, el 26 de julio de 1908, José Carracido llegó a Santiago para presidir el certamen que la Liga de Amigos tenía costumbre de celebrar anualmente en las fiestas del Apóstol. El Eco de Santiago, 26 de julio de 1908, 2.

61 Augusto González Besada fue un político santiagués, que ostentó los cargos de ministro de hacienda, de gobernación, y de fomento, durante el reinado de Alfonso XIII.

62 El diario de Pontevedra, 14 de noviembre de 1908, 1.

${ }^{63}$ Doctor en derecho por la Universidad de Santiago de Compostela, obtuvo la cátedra de derecho romano en la Universidad de Oviedo, permutando posteriormente por la compostelana. Fue alcalde de Santiago entre 1891 y 1895, presidente de la Real Sociedad Económica de Amigos del País entre 1899 y 1906, y rector de la Universidad entre 1906 y 1919. En 1910 fue elegido senador por la provincia de Pontevedra.

${ }^{64}$ El Eco de Santiago, 5 de noviembre de 1906, 1.

65 Gaceta de Galicia, 4 de junio de 1909, 1.

${ }^{66}$ Estas suntuosas piezas son obra de los padre e hijo homónimos Jakob Jägger -que realizaron los dos grandes relieves ovalados centrales-, y Lukas Lang -que se encargó de las exuberantes coronas vegetales de hojas y flores. Cruz Valdovinos, José Manuel. 1997. Platería Europea en España. 13001700. Madrid: Fundación Central Hispano, 329.

67 Las facturas se refieren a una "limpieza y arreglo de cornucopias", trabajo por el que se le pagaron 17 pesetas. ACS. Fábrica. Comprobantes de cuentas de Fábrica, 1897-1901 (IG 1018), separata de 1897.

${ }^{68}$ En la Residencia de Múnich se conserva un juego de ocho cornucopias marcadas por Philipp Jakob IV Drentwett, hacia 1690-1695. Éstas tienen un tamaño algo mayor que las de la catedral de Santiago, y una forma parecida, 
으 con los dos candeleros sobresalientes.

Sin embargo, el trabajo decorativo no

os tan rico, ya que carecen de relieve en

el óvalo central y el marco vegetal está mucho más reducido. Cruz Valdovinos, José Manuel. 1997. Op. cit., p. 334.

${ }^{69}$ El Eco de Santiago, 6 de octubre de 1903, 2; La Época, 14 de octubre de 1903, 3; El Áncora, 9 de octubre de
1903, 3; Gaceta de Galicia, 9 de octubre de 1913, 3; y El Regional, 11 de octubre de 1913, 2.

70 ACS. Fábrica. Comprobantes de cuentas (CB 196), separata de "19161917".

71 Leroy, Mira. 1908. Matériaux et... op. cit. En ambos casos la referen- cia al número de lámina ha sido recortada de la fotografía.

72 Éstas fueron incluidas por Herrero Martín en su tesis de licenciatura: Herrero Martín, María Jesús. 1987. "La orfebrería en las parroquias compostelanas: catalogación". Tesis de licenciatura inédita, Universidad de Santiago de Compostela, 88. 


\section{REFERENCIAS}

Acuña, Xosé Enrique, and José Luis Cabo. 1993. "La fotografía en Galicia." In Galicia Arte, tomo XVI: Arte Contemporáneo (II), edited by Francisco Rodríguez Iglesias, 488-505. A Coruña: Hércules.

Alcálá Subastas. 2013. Catálogo de Alcalá Subastas. Madrid, 3 de diciembre, lote 363.

Anónimo. 1892. Catálogo de la Exposición de Industrias Artísticas de Barcelona. Barcelona: Henrich y Cia.

Anónimo. 1896. Crónica del II Congreso Eucarístico Español, celebrado en Lugo en agosto de 1896. Lugo: Establecimiento tipográfico de G. Castro Montoya.

Anónimo. 1897. Exposición Regional de Lugo. 1896. Catálogo general de expositores y premios adjudicados, resultado de los juegos florales y certámenes musicales. Lugo: Imprenta de Juan A. Menéndez.

Bouza Brey, Fermín. 1962. Platería civil compostelana hasta finales del siglo XIX. Santiago de Compostela: Seminario Padre Sarmiento de Estudios Gallegos.

Cots Morató, Francisco de Paula. 2002. El examen de maestría en el arte de plateros de Valencia: los libros de dibujos y sus artífices. Valencia: Delegación de Cultura.

Cruz Valdovinos, José Manuel. 1997. Platería Europea en España. 1300-1700. Madrid: Fundación Central Hispano.

Dalmases Balañá, Nuria de. 1977. “La orfebrería barcelonesa del s. XVI a través de los Libres de Passanties." D'art, Revista del Departament d'historia de I'arte 3-4, 5-30.

Fernández Casanova, María del Carmen. 1982. "La Exposición regional de Santiago en 1858." Revista de Historia Contemporánea 1, 107137.

García Gaínza, María Concepción. 1991. “El libro de Exámenes de Plateros." Goya 225, 134141.

García Gaínza, María Concepción. 1991. Dibujos antiguos de los plateros de Pamplona. Pamplona: Universidad de Navarra.
Herrero Martín, María Jesús. 1987. “La orfebrería en las parroquias compostelanas: catalogación." Tesis de licenciatura, Universidad de Santiago de Compostela.

Leroy, Mira. 1900-1906. Materiales y documentos del arte español. Barcelona: Librería Perera.

Leroy, Mira. 1908. Matériaux et documents d'art spagnol. Barcelona: Librería Perera.

López Ferreiro, Antonio. 1891. Altar y cripta del apóstol Santiago, reseña histórica desde su origen hasta nuestros días, Santiago de Compostela: Imp. y Enc. del Seminario Conciliar Central.

López Vázquez, José Manuel. 1993. "A escultura neoclásica." In Galicia Arte, Tomo XV: Arte Contemporánea (I), edited by José Manuel López Vázquez \& lago Seara Morales, 28-85. A Coruña: Hércules.

Louzao Martínez, Francisco Xabier. 1991. “Dibujos de platería coruñesa." Goya 221, 284-289.

Louzao Martínez, Francisco Xabier. 1993. “Doña María Ana de Neoburgo en Galicia: la arqueta eucarística y el ostensorio de la Real e Insigne Colegiata de Santa María del Campo de la Coruña." Historia 16 201, 91-104.

Louzao Martínez, Francisco Xabier. 1993. Catálogo del Museo de Arte Sacro de La Coruña. Barcelona: Duplex.

Martín, Fernando. 2001. “Dibujos de platería en la Fundación Lázaro Galdiano." Goya 285, 324-331.

Méndez Hernán, Vicente. 2015. "Aprendices, oficiales, maestros plateros y dibujos de examen en el Madrid de finales del siglo XVIII y comienzos del XIX." In Estudios de platería San Eloy, edited by Jesús Rivas Carmona, 281-302. Murcia: Universidad de Murcia.

Otero Túñez, Ramón. 2004. "José Ferreiro." In Séculos XVIII e XIX, edited by Antón Pulido Novoa, 209-247. Vigo: Nova Galicia Edicións.

Pérez Grande, Margarita. 2008. “Dibujos de examen de plateros de la ciudad de Granada (1735-1747)." Goya 313-314, 257-270.

Pérez Varela, Ana. 2015. "Vida y obra del platero compostelano Ricardo Martínez Costoya." 
Tesis de licenciatura, Universidade de Santiago de Compostela.

Pérez Varela, Ana. 2016. "Obras de José Losada en la colección de platería de la catedral de Santiago de Compostela. Fuentes para su estudio y análisis de las piezas." In Estudios de platería San Eloy, edited by Jesús Rivas Carmona, 505-522. Murcia: Universidad de Murcia.

Pérez Varela, Ana. 2017. "Piezas de Ricardo Martínez Costoya en la colección de platería de la catedral de Santiago de Compostela." In Del taller al museo. Estudios sobre historia del arte, patrimonio y museología en Galicia, edited by Rosa Margarita Cacheda Barreiro \& Carla Fernández Martínez, 276-297. Santiago de Compostela: Andavira.

Pérez Varela, Ana. 2017. "Una tumba para el Hijo del Trueno: La Remodelación Decimonónica de la cripta de la catedral de Santiago y la urna argéntea de sus restos." In Genius Loci: Lugares e Significados. Places and Meanings, edited by Lucía Rosas, Ana Cristina Sousa, y Hugo Barreira, vol. 1, 319-329. Porto: CITCEM.

Sanz Serrano, María Jesús. 1986. Antiguos dibujos de la platería sevillana. Sevilla: Diputación Provincial de Sevilla.

Vila Jato, María Dolores. 1993. "A arquitectura." In Galicia Arte, Tomo XII: Galicia na época do Renacemento edited by María Dolores Vila Jato and José Manuel García Iglesias, 21-199. A Coruña: Hércules.

Yzquierdo Peiró, Ramón. 2017. Los tesoros de la catedral de Santiago de Compostela. Santiago de Compostela: Consorcio de Santiago-Teófilo Edicións. 